\title{
José María Arguedas en la Argentina: notas sobre una búsqueda ${ }^{1}$
}

\author{
Silvia Marcela Graziano \\ Universidad de Buenos Aires \\ silviagraziano@gmail.com
}

A la profesora Susana Zanetti.

Por su generosidad infinita.

Por su vocación latinoamericana.

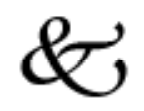

En los años sesenta, las novelas de José María Arguedas eran libros de mesa para las librerías de la Ciudad de Buenos Aires Se armaban las pilas de ejemplares, rápidamente se vendían y se volvían a armar. A partir de la publicación de Las venas abiertas de América Latina de Eduardo Galeano, Los ríos profundos y Todas las sangres, en segundo lugar, constituían los textos obligados de un público lector interpelado por lo latinoamericano.

Como sabemos, José María fue colaborador del suplemento dominical del diario La Prensa de Buenos Aires entre noviembre de 1938 y junio de 1948. Sin embargo, sus vínculos con la Argentina se iniciaron en 1935, con su participación en el concurso literario convocado por la "Revista Americana de Buenos Aires”. Ahora, ¿Cómo se relaciona Arguedas con esa revista?, ¿Qué vínculos posibilitan sus colaboraciones en "La Prensa" de Bs. As?, ¿Cómo entabla relación con la Universidad Nacional de Tucumán?, ¿Cómo conoce a Gonzalo Losada?, ¿Qué amigos esperan su llegada a Buenos Aires?

Las notas que presento se desprenden de una investigación más amplia, en pleno desarrollo ${ }^{2}$. Por tal razón, algunas de ellas tienen carácter provisional.

Estas notas trazan los principales vínculos personales, culturales que $\mathrm{Ar}$ guedas construyó con artistas e intelectuales argentinos desde 1935 hasta su

1 Comunicación presentada en el Congreso de Literatura Latinoamericana y Española- CELEHISUniversidad Nacional de Mar del Plata, Argentina, noviembre de 2011.

2 "La producción narrativa de José María Arguedas en la constitución de la identidad nacional peruana”. Investigación desarrollada en el marco de la especialización en Literatura Hispanoamericana. Instituto Superior del Profesorado “Joaquín V. González”. 
muerte en 1969. Como intentaré demostrar, los vínculos de JMA con el campo intelectual de nuestro país dan continuidad y profundizan las relaciones, los intercambios que, en el Siglo XX, se articulan a partir del encuentro de argentinos y cusqueños en el mismo Cusco.

\section{Argentinos y Cusqueños en la Ciudad Sagrada: el inicio}

En todo el continente, los festejos por el Primer Centenario se presentan como un punto de condensación de la hegemonía del proyecto oligárquico que definió la constitución de los Estados Nacionales Latinoamericanos. El proceso que llevó a la consolidación del nombre de las Ciudades Capitales -fuese Lima, Santiago o Buenos Aires- como sinónimo de la Nación no logró obturar la voluntad de quienes, desde el interior de nuestros países, reclamaban su lugar en lo nacional, al mismo tiempo que se lanzaban a la indagación profunda de los lazos culturales que articulaban áreas americanas particulares.

Ubiquémonos en el Cusco y en el Tucumán de las primeras décadas del Siglo XX.

Tucumán era, hacia 1910, centro geográfico y cultural del noroeste argentino. La llamada "Generación del Centenario", así definida en virtud de los cien años de la Independencia Argentina (1916), dominó, indiscutiblemente, la escena intelectual de las primeras décadas del S. XX. A pesar de las diferencias que el concepto de nación cobraba cuerpo entre ellos, los integrantes de la "Generación del Centenario" (Ernesto Padilla, Alberto Rougés, Ricardo Jaimes Freyre, Miguel Lillo, Juan B. Terán, Juan Heller, Ricardo Rojas y Julio López Mañán) se declararon abiertamente en contra del panamericanismo. Lograron articular un proyecto intelectual y de acción cultural que apuntaba a definir cultural e históricamente la región y que visualizaba "la fraternidad hispanoamericana como una necesidad histórica"3. Fundadores de la Universidad Nacional de Tucumán (Juan B. Terán), promotores de tareas de investigación y recopilación de canciones populares y literatura oral (Ernesto Padilla, Alberto Rougués), institucionalizaron, desde la cultura regional, una visión política de la nación que la generación siguiente profundizaría.

De hecho, Ernesto Padilla y Alberto Rougués facilitaron las tareas de investigación, recopilación y catalogación de los cancioneros populares recogidos por Juan Alfonso Carrizo (Catamarca,1885-Buenos Aires,1957) quien sería miem-

3 “Fraternidad Hispanoamericana”, en Revista de Letras y Ciencias Sociales № 20, dirigida por Ricardo Jaimes Freyre con la colaboración de Juan B. Terán y Julio López Mañán. Citada en Perilli, Carmen (2010). "La Patria entre naranjos y cañaverales. Tucumán y el Primer Centenario". Disponible en www.scielo.org.ar La Revista apareció entre 1904 y 1907. Constituye un hito fundamental para la articulación del campo intelectual del noroeste argentino. 
bro, por Argentina, de la Revista de Folklore Americano, creada por Valcárcel y Arguedas, en 1953.

En 1901, el cusqueño Angel Vega Enríquez fundó el diario El Sol. Bajo su influencia, se formó el núcleo organizador de la huelga universitaria de 1909, de la que Luis Valcárcel y José Uriel García fueron partícipes destacados. Hacia 1908, el movimiento generado en torno a la Universidad, el diario "El Sol" y el Centro Científico, creado a fines del S. XIX, era ya reconocido como "La Escuela Cusqueña”. Lo integraban, entre otros, Valcárcel, Uriel García, José Gabriel Cosio, José Angel Escalante. El grupo orientó su actividad a la defensa del indígena contra la opresión del gamonal, el anticentralismo y la reconquista de la posición orientadora del Cusco en el panorama regional; la exaltación del pasado prehispánico, en especial del imperio incaico y estudios del medio regional y las comunidades indígenas (Valcárcel, 1981: 141)

Para la década del '20, el indigenismo cusqueño ocupaba el centro de la vida intelectual de la región. A través de las colaboraciones a la revista Amauta, dirigida por Mariátegui, alcanzó dimensión nacional.

Dos argentinos visitaron el Cusco en esa etapa: el historiador Roberto Levillier y el escritor Fausto Burgos.

Roberto Levillier (1886-1969). Junto con Manuel Lizondo Borda, Ricardo Jaimes Freyre, Juan B. Terán inició el estudio sistemático de la historia del noroeste argentino. Sus trabajos son considerados pioneros en la investigación sobre la expansión del Imperio Incaico hacia las tierras bajas. Llamado "El historiador de América" por sus contemporáneos, ocupó cargos diplomáticos en España, Portugal, Polonia, la antigua Checoslovaquia, Perú, México, Uruguay. En 1920, integró la delegación que el entonces presidente argentino Hipólito Irigoyen envió a la Sociedad de Naciones. Fundador de la Escuela Argentina de Servicio Exterior. Miembro de la Academia Nacional de la Historia entre 1957 y $1969 .{ }^{4}$

Roberto Levillier llegó a Cusco en 1923 como embajador argentino en Perú. En su homenaje, Luis Valcárcel junto con estudiantes de San Antonio Abad ofrecieron una función de Ollantay y otras obras cusqueñas. Seguramente, la majestuosidad de la puesta en escena (teatro, poesía, música, danza) y su vasto conocimiento de los lazos culturales entre el NOA y el sur peruano impulsaron al diplomático a proponer a Valcárcel que organizara una embajada artística que presentase el arte incaico en Buenos Aires.

4 Entre sus obras se destacan: Orígenes argentinos (1912), La reconstrucción del pasado colonial (1917), El Perú y el Tucumán en tiempos prehistóricos (1928), Chile y Tucumán en el siglo XVI (1928), La Argentina del siglo XVI, Biografía de los conquistadores de Argentina (1933), Don Francisco de Toledo organizador del Perú, $(1935,1939,1942)$, estudio biográfico editado en tres volúmenes; América, la bien llamada, (1947-1948), estudio en defensa del nombre del continente publicado en dos volúmenes; y Las cartas de Américo Vespucio 
A finales de ese mismo año de 1923, Valcárcel, al frente de una delegación integrada por 47 actores, músicos, escritores, pintores y bailarines cusqueños, emprendió el viaje hacia Buenos Aires. La Compañía hizo escala en Puno y en La Paz (Bolivia). Si bien, no es tema de este trabajo la presencia en Buenos Aires de la Misión Peruana de Arte Incaico -asumiendo, con su denominación, el sentido nacional de la visita- sí es de destacar que, en la consideración de Valcárcel, la Misión Peruana de Arte Incaico "hizo más por el Perú que treinta años de diplomacia"5, en tanto propició la relación de Valcárcel con intelectuales argentinos, particularmente, con el tucumano Ricardo Rojas. A partir de ese encuentro, se multiplicarían los intercambios: Valcárcel envío dos ponencias al Congreso de Americanistas reunido en La Plata (1932); los argentinos José Imbelloni, Ricardo Levene y el propio Rojas participaron del Congreso reunido en Lima, en 1939.

Fausto Burgos ${ }^{6}$ nació en Tucumán en 1888. Integrante de "una generación de surgimiento y desarrollo de una corriente americanista", como señala Antonio Pagés Larraya ${ }^{7}$, cultivó el denominado cuento regional. Sus narraciones se ubican, preferentemente, en Tucumán, Jujuy y la Puna. En 1928, llegó a Cusco, en busca de las continuidades culturales entre su ciudad natal y el sur andino. Allí conoció a Valcárcel y a Uriel García. Impresionado por la campaña indigenista organizada por los cusqueños, los invitó a publicar en el diario La Prensa de Buenos Aires, de cuyo suplemento dominical era asiduo colaborador.

Conocida es la trascendencia de Valcárcel en la vida académica y profesional de José María Arguedas. Se conocieron en Lima, en 1931. Un año antes, Valcárcel se había incorporado al plantel docente de la Universidad Mayor Nacional de San Marcos; José María era un joven de 20 años que iniciaba sus estudios superiores.

La primera colaboración de JMA para el diario La Prensa de Buenos Aires, "Simbolismo y poesía de dos canciones populares quechuas", fue publicada el 27 de noviembre de 1938. Aparece en la primera página del suplemento dominical. La diagramación -un recuadro insertado entre las columnas de un cuento- y el lugar que el artículo ocupa sugieren que el autor de ese cuento es quien presenta al desconocido articulista peruano.

5 Valcárcel, Luis E. Memorias. Editado por José María Matos, José Deustua y José Luis Rénique. Lima, Instituto de Estudios Peruanos (IEP), 1981.

6 Fausto Burgos (1888-1953). Nació en Tucumán y murió en San Rafael, Mendoza. Pasó largas temporadas en Catamarca, La Plata, Salta y Jujuy, dedicado al estudio y la docencia. Publicó dos novelas, Kanachis Sorucho y El salar, además de varios volúmenes de cuentos y poesía. Hacia 1921 era colaborador de "La novela del Norte”, revista cultural publicada en Tucumán de la que también participaba Juan B. Terán. Integró, junto con Juan Alfonso Carrizo, el Comité Editorial de la Revista Sustancia (1939-1943).

7 Pagés Larraya, Antonio. Cuentos de Nuestra Tierra. Estudio preliminar, selección y notas a cargo de Antonio Pagés Larraya. Editorial Raigal, Buenos Aires, 1952. 
El cuento es Yáhuar, enviado por Fausto Burgos desde el Valle de Vilcanota, Cusco.

Es de destacar que el tercer artículo de José María ${ }^{8}$ ya ocupa las tres cuartas partes de la página y aparece acompañado de fotos del cusqueño Martín Chambi.

Los temas andinos no resultaban extraños para el público lector de LPBA. Baste recordar las colaboraciones de Clorinda Mattos de Turner durante su exilio en Argentina.

En reconocimiento a su labor de difusión del folklore peruano a través de los artículos publicados en LPBA, la Universidad Nacional de Tucumán nombró a Arguedas miembro correspondiente en Lima de su Instituto de Historia, Linguística y Folklore, en 1942. Como informa la Biblioteca Central de la UNT, ese Instituto fue disuelto por la última dictadura, sus miembros, cesanteados y la documentación se halla dispersa en distintos organismos oficiales. Sin embargo, ciertos datos invitan a pensar que JMA se vinculó con la UNT a través del Padre Lira.

El Padre Jorge Lira y José María se conocieron en el Colegio Nacional Mateo Pumaccahua de Sicuani (Cusco), donde Arguedas fue nombrado profesor en 1939, tras ocho meses de prisión en El Sexto.

El sacerdote cusqueño conoció a las autoridades de la Universidad de Tucumán en Lima, hacia 1940, a quienes entregó una copia de su Diccionario Quechua-Castellano/Castellano-Quechua. Un año más tarde, el Padre Lira recibía la notificación de que su diccionario sería publicado, además de una invitación para conocer Tucumán.

En 1942, año del nombramiento de Arguedas, Lira viajó a Tucumán como invitado de honor de la UNT. Dio varias conferencias en esa ciudad. En el prólogo del Diccionario, publicado finalmente en 1944, agradecía, especialmente, a Rafael Jijena Sánchez, por entonces Secretario General y Jefe de la Sección Folklore del Instituto que galardonara a Arguedas.

Es también probable que el encuentro entre Burgos y los cusqueños determinara la participación de Arguedas en el concurso literario organizado por la Revista Americana de Buenos Aires. La publicación -que merece una investigación específica- apareció entre 1924 y 1939. Fundada por V. Lillo Catalán, Alberto Palomeque y C. Barros Conde, se presentaba como "un vehículo del pensamiento argentino y órgano de relación internacional que quiere agrupar a los escritores argentinos y extranjeros (latinoamericanos) partidarios de la independencia de pensamiento".

Para los años '30, contaba con colaboradores chilenos, ecuatorianos, mejicanos, paraguayos, brasileños, uruguayos, venezolanos, españoles y, entre los

8 Arguedas, José María. “Los doce meses” en LPBA, 17-12-1939. 
argentinos, se destacan los tucumanos Joaquín Castellanos y Juan Pablo Echagiie. Entre los colaboradores peruanos, figuran Héctor Velarde, Alberto Ureta, Vladimiro Bermejo y Humberto Pacheco. Este último, cuentista indigenista de inspiración gonzálezpradista, era el Director de "Alma Quechua", revista cusqueña que apareció entre 1933 y 1936.

La publicación, de carácter mensual, ofrecía sus páginas a "los intelectuales cuyas producciones continúan inéditas por falta de medios económicos o de relaciones". Los escritores americanos, españoles y portugueses encontrarían en ella "un medio para establecer un sólido vínculo de comprensión y afecto"'. Los trabajos recibidos a lo largo de un año participaban del concurso de narrativa y de poesía. Es así que Así bajaron los perros del peruano, y amigo de Arguedas, Manuel Moreno Jimeno figura en el listado de obras recibidas durante $1934^{10}$. José María obtuvo el segundo premio de narrativa, en 1935, con Agua. En 1937, publicaría el cuento que resultaría posteriormente, integrado a su primera novela, Yawar Fiesta (1941).

\section{El encuentro con Gonzalo Losada: la puerta a América Latina}

Gonzalo Losada conoció a Arguedas en Lima, antes de la publicación de LRP. Así lo plantea en un artículo publicado en la revista Runa: "a Arguedas le animé y le estimulé para que escribiera ya que nosotros le publicaríamos con mucho gusto. Empezamos nada menos que con Los ríos profundos..."11

La vinculación con Losada, no sólo abriría para Arguedas el mercado editorial latinoamericano y europeo sino también el mundo de relaciones amicales e intelectuales que el editor mantenía en Buenos Aires. El escritor paraguayo Elbio Romero, exiliado en esta ciudad, recuerda la presencia de José María en la casa porteña de Rafael Alberti, obviamente, en compañía de Losada. ${ }^{12}$ Sería, justamente, Elbio Romero quien recomendaría la publicación de Los ríos profundos a editores checoslovacos. ${ }^{13}$

En 1960, tuvo lugar en Buenos Aires, la III Feria del Libro Americano, auspiciada por la O.E.A y fuertemente impulsada por el propio Losada. Como afirma Jorge Lafforgue ${ }^{14}$, quien conoció a Arguedas en esa oportunidad, Javier Fer-

9 Revista Americana de Buenos Aires № 65, septiembre de 1929.

10 Revista Americana de Buenos Aires № 134. Junio de 1935

11 Artículo aparecido en la Revista Runa №5, Instituto Nacional de Cultura, citado en "La Editorial Losada: una historia abierta". Madrid: s/f

12 "Don Gonzalo visto por Elbio Romero" en "La Editorial Losada: una historia abierta”, op.cit.

13 Carta del editor checoslovaco V. Oleriny del 23-07-63, publicada en Carmen María Pinilla (ed.)

"Apuntes inéditos. Celia y Alicia Bustamante en la vida de José María Arguedas", Lima. PUCP: 2007

14 Entrevista con el Prof. Jorge Lafforgue. Junio de 2011. Editor, para la Editorial Losada, de Relatos Completos de José María Arguedas en 1967. 
nández fue el gran impulsor del protagonismo de la delegación peruana en el evento -integrada, entre otros, por José María y Ciro Alegría.

El escritor Javier Fernández, con quien Arguedas mantenía una relación personal, era Agregado Cultural de la embajada argentina en Perú. Había iniciado su carrera diplomática junto a Alfredo Palacios. Frecuentador de los ambientes literarios de los 40 y 50, militaba con Dardo Cúneo en el Partido Socialista Argentino. En los 50, ambos se vincularon al proyecto político liderado por Arturo Frondizi y Rogelio Frigerio. Durante el gobierno de Frondizi (1958-1962), Cúneo se desempeñó primero como Secretario de Prensa de la Presidencia y luego como representante argentino ante la Organización de Estados Americanos.

Concluida la Feria, Arguedas visitó una fábrica de alfombras en compañía de Bernardo Canal Feijoó, ganador del Premio Ensayo 1960 otorgado por la Editorial Losada. Posteriormente, se dirigió a la Universidad de La Plata, donde mantuvo un encuentro con los estudiantes peruanos de esa Casa de Estudios. Vinculado a este viaje, hay un dato que cobra singular importancia. En el artículo en el que José María reseña su estancia en Buenos Aires ${ }^{15}$, destaca "la integración cultural de América Latina, tan necesaria y acaso más fácil que la integración económica, ha comenzado ya. La actual Embajada Argentina y su Agregado Cultural, Javier Fernández, han abierto el camino de Buenos Aires-Lima-Cusco", denominando "eje espiritual" al flujo de intercambios abierto en los '20 y que él mismo integraba.

Tampoco resulta anecdótica la presencia de Canal Feijoó. Santiagueño de nacimiento, estuvo vinculado a la Generación Tucumana del Centenario. Si bien su nombre quedó asociado a la literatura y el folklore, el trabajo de Canal Feijoó ${ }^{16}$ desbordó esos campos. Menciono su libro "Confines de Occidente. Notas para una sociología de la cultura" (1954), en el que analiza, entre otros temas, la relación entre independencia política y autonomía cultural y el impacto en la subjetividad que provoca la imposición colonial en los pueblos dominados.

15 Arguedas, José María. "Perú y la Argentina”. Idea, junio de 1960.

16 Bernardo Canal Feijoó (Santiago del Estero, 1897 - Bs. As., 1982). Poeta, ensayista, dramaturgo, historiador. Principal animador de la agrupación cultural "La Brasa" (Santiago del Estero,1925-1947), empresa a la que se unieron Waldo Frank, Rafael Alberti, Roger Caillois, entre otras personalidades extranjeras. El grupo no contó con una publicación propia. Publicaban en los diarios La Nación, Crítica y en la Revista Sur, dirigida por Victoria Ocampo. Privilegiaron sus colaboraciones para el periódico "La vida literaria", fundado y dirigido por Samuel Glusberg, quien mantenía asidua correspondencia con Carlos José Mariátegui. Canal Feijóó fue, además, uno de los más destacados organizadores del "Primer Congreso Regional de Planificación Regional” celebrado en su provincia natal en 1946. Radicado en Buenos Aires, participó activamente de la Revista Sur. Decano de la Facultad de Humanidades de la Universidad Nacional de La Plata, Secretario de Cultura de la Universidad de Buenos Aires y Presidente de la Academia Argentina de Letras. 
Este trabajo de Feijoó es ampliamente citado por Héctor P. Agosti ${ }^{17}$, el introductor de Antonio Gramsci en la Argentina, director de los Cuadernos de Cultura y amigo también de Arguedas, en su libro Nación y Cultura, libro que seguramente el peruano conocía.

Una última referencia. EUDEBA publicó Poesía Quechua en 1965, con una tirada de 10.000 ejemplares. Con anterioridad a ese año, en una fecha que aún no he podido precisar, José María, camino a Chile, visitó la sede de la editorial para firmar el contrato.

Susana Zanetti ${ }^{18}$ recuerda que JMA ya era amigo de Horacio Achával. En esa oportunidad, Arguedas llegó acompañado de José Bianco, responsable de la colección "Genio y figura". Bianco y Arguedas se habían conocido en 1959, en casa de Victoria Ocampo, después de que la Comisión Peruana de Intercambio Cultural integrada por José Jiménez Borja, José Durand, José Miguel Oviedo, José María Arguedas y encabezada por Luis Valcárcel, se entrevistara con el Presidente Arturo Frondizi.

En esa visita -que terminó en cena- el tucumano Oscar Díaz (el Negro Díaz para sus compañeros), ilustrador de la editorial, arregló con José María su viaje a Perú. Desde Lima, ambos hicieron el camino Lima-Cusco a caballo, travesía que duró cuatro días visitando distintos pueblos de la sierra sur.

José Bianco ${ }^{19}$, Héctor P. Agosti y José María volverían a reunirse en el Encuentro de Escritores Americanos desarrollado en Concepción (Chile, 1962), en el que la responsabilidad política de los escritores latinoamericanos aparece tematizada (Gilman:71). Ese encuentro, punto inicial del intento de constituir una asociación gremial para todo el continente, tuvo continuidad en Génova (1965), Arica (1966), México (1967). En este último, del que participaron Arguedas, Bianco, y alrededor de un centenar de artistas e intelectuales latinoamericanos, el planteo fue más lejos:

17 Héctor P. Agosti (1911-1984) Uno de los teóricos del Partido Comunista Argentino. Prolífero ensayista político, reconoce sólo a Mariátegui y a Mella como auténticos intelectuales revolucionarios en su primer libro El hombre prisionero de 1938.

18 Entrevista con la Prof. Susana Zanetti, 2011. Susana Zanetti (Argentina, 1933) Junto con Boris Spivacow, Horacio Achaval, Gregorio Selser, Oscar Díaz, José Bianco, Obelar, Miriam Polak, Beatriz Sarlo y Aníbal Ford integró el equipo de producción de la legendaria EUDEBA y posteriormente, del Centro Editor de América Latina (CEAL). Profesora titular de Literatura Latinoamericana en la Facultad de Filosofía y Letras de la Universidad de Buenos Aires. Actualmente, profesora consulta de esa Facultad. Profesora titular de Literatura Latinoamericana en la Facultad de Humanidades de la Universidad Nacional de La Plata. Dirige la revista del Centro de Teoría y Crítica, Orbis Tertius.

19 José Bianco (1908-1986). Novelista y traductor argentino. Secretario de Redacción de la revista Sur, dirigida por Victoria Ocampo, puesto del que fue separado por su visita a Cuba y su participación como jurado del Premio Casa de las Américas. Miembro del equipo de producción de EUDEBA y del C.E.A.L. 
... forjar la integración cultural en el ámbito latinoamericano, discutir acerca de las formaciones gremiales, la defensa de los derechos profesionales, el incremento de la circulación de obras, el estímulo a la información bibliográfica (Gilman: 131).

De dar nacimiento a la Asociación Latinoamericana de Escritores se trataba, ahora, de constituir la Comunidad Cultural Latinoamericana.

\section{Palabras finales}

Hasta aquí, las primeras líneas de investigación. Más que un inventario de amigos y relaciones se impone la necesidad de reconocer su sentido.

La urdimbre de textos, figuras, intercambios enlazada por cusqueños y tucumanos en las primeras décadas del Siglo XX resulta de la exploración de lo negado por los festejos del Primer Centenario: el sentido profundo que el proceso emancipatorio cobraba para los pueblos latinoamericanos. Se inscribe en el mandato abierto por Martí y reclamado por Rodó: "Lograr que acabe el actual desconocimiento de América por América misma"20.

Nacidas de estas otras Generaciones del Centenario, aquellas articuladas desde los centros culturales regionales, los lazos de José María Arguedas con el campo intelectual argentino dan continuidad y profundizan el mandato.

Nada mejor que recuperar su palabra al referirse al Encuentro de Escritores en Arica (1962)

... todo esto apareció como fuente de integración posible: vertebrar en un conjunto fecundo individualidades complejas en sí mismas, y diferentes, en un conjunto mayor y poderoso...No se integra lo ya articulado o uniforme. Pero no fueron las razones culturales, geográficas e históricas las que aparecieron como agentes principales que impulsarían la posible integración: ella se hará por causas que afectan cada vez más directamente la independencia política y económica de los países latinoamericanos...Y en una América Latina integrada, por intereses económicos más aún que políticos, el ámbito para las artes, para todos los géneros de la creación humana será mucho más vasto, original y auténtico. El ámbito todo, las fuentes de la creación y todo lo creado ${ }^{21}$

Hacia allí seguimos yendo...

20 Carta de Rodó a Manuel Ugarte del 25-04-1896. Citado por Susana Zanetti en "Modernidad y religación: una perspectiva continental (1880-1916)" en Ana Pizarro (Organizadora) América Latina. Palabra, Literatura e Cultura. Campinas, 1994.

21 Arguedas, José María. La Literatura como testimonio y contribución. Testimonio publicado por Manuel Moreno Jimeno bajo el título Arguedas: Documentos y testimonios. Mimeo. Universidad Agraria La Molina, 1973. 


\section{Referencias bibliográficas}

ARGUEDAS, José María (1960). “Perú y la Argentina”. En Idea: Lima, junio

ARGUEDAS, José María (2000). “La literatura como testimonio y contribución”. En Cuadernos arguedianos, II Epoca, Año $3 \mathrm{~N}$ ㅇ.

ARGUEDAS, José María (1989). Indios, mestizos y señores. Lima: Editorial Horizonte.

GILMAN, Claudia (2003). Entre la pluma y el fusil. Debates y dilemas del escritor revolucionario en América Latina. Buenos Aires: Siglo XXI Editores.

KUON ARCE, Elizabeth/ Gutiérrez Viñuales, Rodrigo/ Gutiérrez, Ramón/ Viñuales, Graciela María (2009). Cuzco-Buenos Aires. Ruta de la intelectualidad americana (19001950). Lima: Fondo Editorial Universidad de San Martín de Porres.

LAGMANOVICH, David. El Norte Argentino: una realidad literaria. En Revista de la Universidad Nacional de Santa Fe № 69, octubre-diciembre de 1966.

LASTRA, Pedro (2000). Imágenes de José María Arguedas. En eído y anotado. Letras chilenas e hispanoamericanas. Imágenes /Encuentros. Chile: Editorial Lom.

PAGÉS LARRAYA, Antonio (1952). "Cuentos de Nuestra Tierra”. Estudio preliminar, selección y notas a cargo de Antonio Pagés Larraya. Buenos Aires: Editorial Raigal, Buenos Aires.

PERILLI, Carmen (2010). La Patria entre naranjos y cañaverales. Tucumán y el Primer Centenario. Disponible en www.scielo.org.ar

PINILLA, Carmen María (ed.) (2007). Apuntes inéditos. Celia y Alicia Bustamante en la vida de José María Arguedas. Lima. Fondo Editorial PUCP.

PODERTI, Alicia (2005). De Güemes a Perón. Revistas culturales y periodismo en Argentina. Buenos Aires: Ed. Nueva Generación.

VALCÁRCEL, Luis E (1981) Memorias. Editado por José María Matos, José Deustua y José Luis Rénique. Lima: Instituto de Estudios Peruanos (IEP).

ZANETTI, Susana (1994) Modernidad y religación: una perspectiva continental (1880-1916). En Pizarro, Ana (edit.), América Latina. Palabra, Literatura e Cultura. Campinas: Editora da Universidade Estadual de Campinas. 